\title{
Functionele en oncologische uitkomsten van salvage cryochirurgie voor lokaal recidief prostaatcarcinoom na radiotherapie
}

\author{
Siberyn T. Nuijens (D) - L. Exterkate · Siebren Dijkstra · Max Peters · Diederik M. Somford · Henk Vergunst
}

Geaccepteerd op: 17 augustus 2021 / Published online: 21 september 2021

(C) The Author(s) 2021

Samenvatting Het doel van deze studie was de oncologische en functionele uitkomsten van salvage cryochirurgie (sCC) te beoordelen bij lokaal recidief prostaatcarcinoom na radiotherapie (rrPCA). De studie werd uitgevoerd bij 169 patiënten. Er vond retrospectieve analyse plaats van recidiefvrije overleving (BRFS), algehele overleving, metastasevrije overleving, androgeendeprivatietherapie (ADT)-vrije overleving, functionele uitkomsten en complicaties. De mediane follow-up was 36 maanden (IQR = 18-66). BRFS na vijf en acht jaar was 52\% $(95 \%-\mathrm{BI}=43-62)$ en $45 \%(95 \%-B I=35-57)$, respectievelijk. PSA bij initiële diagnose, de initiële behandeling, het interval tussen de primaire behandeling en SCS, leeftijd bij SCS en post-SCS PSA-nadir waren significante voorspellers van BRFS. De vijf-jaars ADT-vrije overleving was $70 \%$ $(95 \%-B I=62-79)$. Complicaties van graad III of hoger traden op bij $1,2 \%$ van de patiënten. Bij $19 \%$ en $92 \%$ van de patiënten trad new onset urine-incontinentie respectievelijk erectiele disfunctie op, bij $6,5 \%$ persisterende urinaire fistels en bij $12 \%$ desobstructie. SCS heeft aanvaardbare oncologische resultaten, maar kan gepaard gaan met ernstige complicaties (urineincontinentie, stenose en fistels).

Trefwoorden cryochirurgie $\cdot$ prostaatcarcinoom . salvagebehandeling $\cdot$ radiotherapie $\cdot$ uitkomsten

Dit artikel is een vertaling van Exterkate L, Peters M, Somford DM, Vergunst H. Functional and oncological outcomes of salvage cryosurgery for radiorecurrent prostate cancer. BJU Int. 2021;128:46-56. https://doi.org/10.1111/bju.15269.

drs. S. T. Nuijens $(\bowtie)$

afdeling Urologie, Canisius-Wilhelmina Ziekenhuis,

Nijmegen, Nederland

sieb.nuijens@radboudumc.nl
Functional and oncological outcomes of salvage cryosurgery for radiorecurrent prostate cancer

Abstract In this study functional and oncological outcomes of salvage cryosurgery (SCS) for radiorecurrent prostate cancer (rrPCa) were evaluated in 169 patients. Recurrence free survival (BRFS), overall survival, metastasis free survival, androgen deprivation therapy (ADT) free survival, functional outcomes and complications were retrospectively analyzed. Median follow-up was 36 months (IQR=18-66). BRFS after five and eight years was 52\% $(95 \%-\mathrm{CI}=43-62)$ and $45 \%$ $(95 \%-\mathrm{CI}=35-57)$, respectively. PSA at initial diagnosis, initial treatment, interval between primary treatment and SCS, age at SCS, and post-SCS PSA-nadir were significant factors for BRFS. Five-year ADT-free survival was $70 \%(95 \%-\mathrm{CI}=62-79)$. Grade III or more complications occurred in $1.2 \%$ of patients. $19 \%$ and $92 \%$ of patients had new-onset urinary incontinence respectively erectile dysfunction, $6.5 \%$ persistent urinary fistula and $12 \%$ needed desobstruction. SCS has acceptable oncological outcomes, but can be accompanied by serious complications (urinary incontinence, stenosis and fistula).

Keywords cryosurgery $\cdot$ prostate cancer $\cdot$ salvage treatment $\cdot$ radiotherapy $\cdot$ outcomes

\section{Introductie}

Uitwendige radiotherapie (EBRT) en brachytherapie zijn gebruikelijke behandelingen bij patiënten met een gelokaliseerd prostaatcarcinoom (PCa). Echter, afhankelijk van de risicoclassificatie voorafgaand aan de behandeling ontstaat bij $12-69 \%$ van deze patiënten een lokaal recidief [1]. Een lokaal recidief van PCa na radiotherapie (radiorecurrent PCa; rrPCa) wordt meestal behandeld met (uitgestelde) andro- 
geendeprivatietherapie (ADT), terwijl slechts 2-3\% van deze patiënten een salvagebehandeling ondergaat, zoals high-intensity focused ultrasound (HIFU), salvage brachytherapie, salvage radicale prostatectomie of salvage cryochirurgie (sCC) $[2,3]$. sCC is een minimaal invasieve behandeling, maar de middellange en langetermijnuitkomsten zijn nog nauwelijks onderzocht. Het doel van deze studie is de oncologische en functionele uitkomsten alsook de bijkomende morbiditeit van sCC voor gelokaliseerd rrPCa vanuit een expertisecentrum te rapporteren.

\section{Patiënten en methoden}

\section{Salvage cryochirurgie (sCC)}

Voor de uitvoering van het onderzoek is toestemming verkregen van de institutionele medisch-ethische toetsingscommissie.

De uitkomsten van sCC na EBRT (met of zonder (neo)adjuvante ADT) of brachytherapie werden retrospectief geanalyseerd. In ons centrum kwamen alleen patiënten met een lokaal rrPCa en zonder lymfekliermetastasen of metastasen op afstand, een lange PSAverdubbelingstijd ( $>6-12$ maanden) en een levensverwachting van $>10$ jaar geacht in aanmerking voor sCC.

Alle patiënten hadden een biochemisch recidief (BR) overeenkomstig de Phoenix-definitie (PSA-nadir $+2 \mathrm{ng} / \mathrm{ml}$ ), alsook een lokaal recidief, hetgeen was vastgesteld via biopsie voorafgaand aan de sCC. De biopsie voorafgaand aan de sCC vond plaats door middel van systematisch transrectale echografiegeleide (TRUS), of cognitieve MRI-geleide (random + targeted) biopsie of door middel van MRI/TRUS-fusiebiopsie. Sampling van de vesicula seminalis werd uitgevoerd wanneer er op beeldvorming die aan de sCC voorafging, verdachte laesies op beeldvorming te zien waren. Systemische ziekte werd uitgesloten met behulp van botscintigrafie, CT-scan, multiparametrische MRI (mpMRI) en meer recent ook met behulp van PSMA PET/CT. Ook patiënten met (neo)adjuvante $\mathrm{ADT}$ ten tijde van primaire radiotherapie werden geïncludeerd. Eventuele ADT werd minimaal drie maanden voor de sCC gestaakt. De sCC-behandelingen werden door een enkele operateur uitgevoerd hetzij onder algehele, hetzij met spinale anesthesie. De 1,47 mm 17-G IceSeed ${ }^{\circledR}$ - (bij een prostaatlengte van $<35 \mathrm{~mm}$ ) of de IceRod $^{\circledR}$-naalden (bij een prostaatlengte van $>35 \mathrm{~mm}$ ) (Galil Medical Inc., St Paul, MN, USA) werden TRUS-geleid transperineaal ingebracht in de prostaat. Op indicatie werden twee cryonaalden ingebracht in de rectumwand voor actieve opwarming. In de prostaat en in de rectumwand werden thermosensoren geplaatst. Er werd een transurethrale verwarmingskatheter geplaatst nadat perforatie van de urethra was uitgesloten met behulp van urethrocystoscopie. Vervolgens werden twee vriescycli met argon/heliumgas uitgevoerd met als doeltemperatuur $\leq-40^{\circ} \mathrm{C}$ (fig. 1). Tijdens de ingreep werden de di-

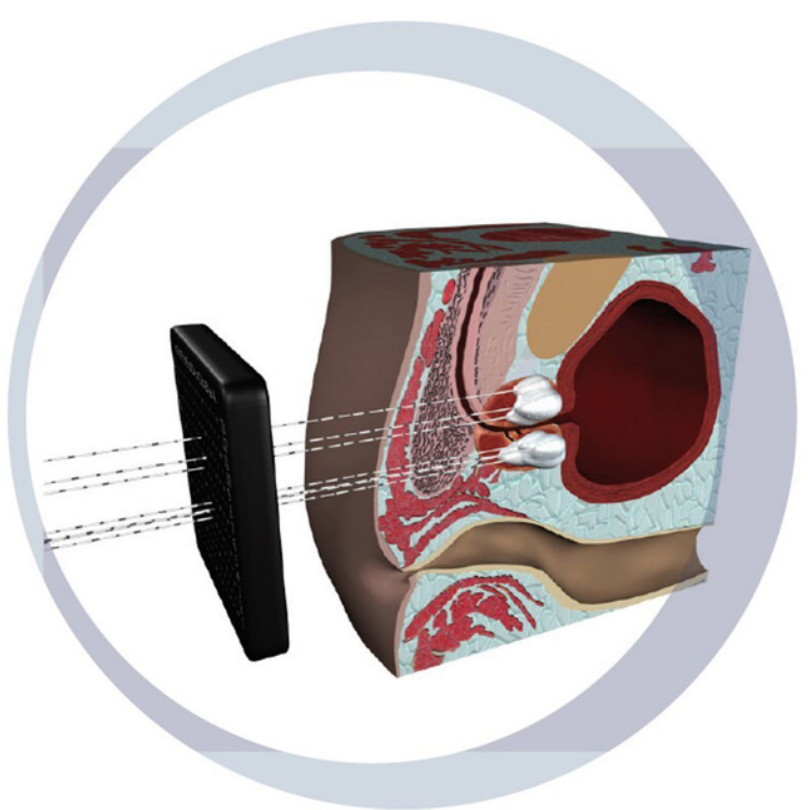

Figuur 1 Salvage cryochirurgieprocedure: een impressie

mensie en contouren van de ijsballen beoordeeld met TRUS. Afhankelijk van de grootte en locatie van de tumor werd er gekozen voor behandeling van de hele prostaat of voor hemi-ablatie. Peroperatief werd er een suprapubische katheter (incidenteel een transurethrale katheter) geplaatst en 7-14 dagen in situ gelaten. Patiënten werden de volgende dag ontslagen. Ciprofloxacine, tamsulosine en macrogol werden voorgeschreven voor respectievelijk twee, vier tot zes en zes weken.

\section{Variabelen en uitkomsten}

Variabelen die werden meegenomen in de analyse waren: leeftijd, primaire behandeling, initiële PSAwaarde, initieel klinische T-stadium, initiële Gleasonscore, D'Amico risicogroep, interval tot sCC, pre-sCC PSA-waarde, pre-sCC prostaatvolume, pre-sCC PSAdichtheid (PSAD), pre-sCC Gleason-score, pre-sCC beeldvorming (MRI en PSMA PET/CT), pre-sCC PSAnadir, en interval tot PSA-nadir [4].

Complicaties werden gescoord met het ClavienDindosysteem [5]. Postoperatief werd de PSA-waarde iedere drie tot zes maanden bepaald. Functionele door de patiënt gerapporteerde uitkomsten werden gescoord op verschillende tijdsintervallen (na 12 maanden of bij de laatste follow-up wanneer deze $<12$ maanden bedroeg). Urine-incontinentie (UI) werd gedefinieerd als het gebruik van $>1 \mathrm{pad} / 24$ uur. Erectiele disfunctie (ED) werd gedefinieerd als tumescentie die insufficiënt is voor geslachtsgemeenschap. De duur van de follow-up werd berekend vanaf de datum van sCC tot de laatste follow-up of overlijden. De primaire uitkomst was biochemical recurrencefree survival (BRFS) volgens de Phoenix-definitie. De secundaire uitkomsten waren biochemical recurrence 
(BR) gedefinieerd als pre-sCC PSA $>0,5 \mathrm{ng} / \mathrm{ml}$, overall survival (OS), metastasis-free survival (MFS), en ADT-free survival. Voor analyse van laatstgenoemde overleving werd het feitelijke startmoment van ADT als inclusiecriterium gehanteerd, waardoor patiënten met een BR die op dat moment nog niet begonnen waren aan ADT, geëxcludeerd werden. Initieel werd bij een oplopend PSA (korte PSA-verdubbelingstijd; $<4-6$ maanden) herstadiëring verricht met behulp van MRI, CT en/of botscintigrafie. Meer recent werd hiervoor PSMA PET/CT gebruikt. Biopsie na de behandeling vond in slechts een enkel geval plaats, zoals bij significante PSA-stijging (korte PSA-verdubbelingstijd) en/of bij een verdenking op recidiefziekte op basis van beeldvorming.

\section{Statistische analyse}

\section{Descriptieve statistiek}

Continue variabelen werden weergegeven met het gemiddelde +/- standaarddeviatie (SD) of als de mediaan met de interkwartielafstanden (IQR). Verschillen werden getest met de ongepaarde T-toets of de Mann-Whitney-U-test. De Fisher-exacttest werd gebruikt voor het testen van verschillen in categoriale variabelen. Toxiciteit is gepresenteerd als het deel van de patiënten met kortetermijncomplicaties, UI en ED.

\section{Ontbrekende data en imputatie}

Ontbrekende data werden beschouwd als zijnde willekeurig en hiertoe werden meerdere imputaties uitgevoerd. In totaal werden er 20 nieuwe datasets gecreëerd waarin de schattingen gemiddeld werden.

\section{Modellen}

Er werd een Cox-regressieanalyse uitgevoerd, waaruit hazard ratio's (HR's) met 95\%-betrouwbaarheidsinterval (BI) voortkwamen. Voor de multivariabele analyses werd een combinatie van significante variabelen uit de univariabele analyse samen met klinisch relevante variabelen geïncludeerd. Hierbij werd rekening gehouden met het aantal events dat beschikbaar was (volgens de regel van 10 events per predictor) [6].

Multicollineariteit werd nagegaan in de eerste stap van het model. Indien van toepassing werden klinisch minder relevante variabelen vervolgens verwijderd uit het multivariabele model. Interacties tussen de variabelen werden niet onderzocht.

\section{Software}

Descriptieve statistiek werd uitgevoerd met Statistical package for Social Sciences (SPSS ${ }^{\circledR}$ ), versie 24.0 (IBM Corp., Armonk, NY, USA). Verder werd de R-language environment (versie 3.5.3) gebruikt (beschikbaar op http://www.r-project.org/). Een $p \leq 0,05$ werd beschouwd als statistisch significant.

\section{Resultaten}

\section{Patiëntkarakteristieken}

In totaal vond retrospectieve analyse plaats van 169 opeenvolgende rrPCa-patiënten (gemiddelde leeftijd 67,8 $\pm 5,7$ jaar; mediaan pre-sCC PSA $5,5 \mathrm{ng} / \mathrm{ml}$ $(\mathrm{IQR}=3,5-9,1))$ die allen tussen mei 2006 en juni 2018 waren behandeld met sCC. In tab. 1 staat een samenvatting van de patiëntkarakteristieken. De mediane tijd van primaire behandeling tot sCC was 7 jaar (IQR = 5-9). Pre-sCC PSA-nadir $\leq 0,1 \mathrm{ng} / \mathrm{ml}$ werd bereikt bij 65 patiënten (38\%); 28 (17\%) patiënten hadden een PSA-nadir van $0,1-0,5 \mathrm{ng} / \mathrm{ml}$ en 76 patiënten (45\%) hadden een PSA-nadir $>0,5 \mathrm{ng} / \mathrm{ml}$. Mediane follow-up was 36 maanden $(\mathrm{IQR}=18-66)$ met een minimum follow-up van vijf jaar bij 54 patiënten (tab. 2).

Tabel 1 Patiëntkarakteristieken $(n=169)$

\begin{tabular}{|l|c|}
\hline leeftijd (gem. \pm SD), jaren & $68 \pm 5,7$ \\
\hline initieel PSA (mediaan, IQR), ng/ml & $14,3(8,7-27)$ \\
\hline primair tumorstadium, $n(\%)$ & \\
\hline - cT1 & $34(20)$ \\
\hline - cT2 & $50(30)$ \\
\hline - cT3 & $70(41)$ \\
\hline - cT4 & $1(0,6)$ \\
\hline - onbekend & $14(8,3)$ \\
\hline primaire Gleason-score, $n(\%)$ & \\
\hline - 6 6 & $63(37)$ \\
\hline - 7 & $51(30)$ \\
\hline - $\geq 8$ & $29(17)$ \\
\hline - onbekend & $26(15)$ \\
\hline primaire d'Amico-risicogroep, $n$ (\%) & \\
\hline - hoog & $101(60)$ \\
\hline - gemiddeld & $37(22)$ \\
\hline - laag & $18(11)$ \\
\hline - onbekend & $13(8)$ \\
\hline primaire behandeling, $n(\%)$ & \\
\hline - EBRT zonder (neo)adjuvante ADT & $63(37)$ \\
\hline - EBRT met (neo)adjuvante ADT & $75(44)$ \\
\hline - brachytherapie & $31(18)$ \\
\hline PSA voor SCS (mediaan, IQR), ng/ml & $5,5(3,5-9,1)$ \\
\hline Gleason-score voor SCS, $n$ (\%) & \\
\hline - $\leq 6$ & $29(17)$ \\
\hline - 7 & $61(36)$ \\
\hline - $\geq 8$ & $52(31)$ \\
\hline - onbekend & $27(16)$ \\
\hline prostaatvolume voor SCS (gem. \pm SD), ml & $26 \pm 9,1$ \\
\hline tijdsinterval tussen eerste behandeling tot SCS (mediaan, & $7(5-9)$ \\
\hline IQR), jaren & \\
\hline salvage cryotherapie, $n$ (\%) & $154(91)$ \\
\hline - volledige ablatie & \\
\hline - hemi-ablatie & \\
\hline ADT androgeendeprivatietherapie, EBRT external beam radiation therapy, \\
\hline IQR interkwartielrange, SCS salvage cryochirurgie \\
\hline
\end{tabular}


Tabel 2 Oncologische en functionele uitkomsten van salvage cryochirurgie $(n=169)$

\begin{tabular}{|l|c|}
\hline follow-up na SCS (mediaan, IQR), maanden & $36(18-66)$ \\
\hline PSA-nadir (mediaan, IQR), ng/ml & $0,3(0,1-1,8)$ \\
\hline tijd tot PSA-nadir (mediaan, IQR), maanden & $1(1-2)$ \\
\hline Clavien-Dindo (highest score per patient), $n(\%)$ & \\
\hline - graad I & $71(42)$ \\
\hline - graad II & $31(18)$ \\
\hline - graad Illa & $2(1,2)$ \\
\hline type complicatie, $n(\%)$ & \\
\hline - hematurie & $31(18)$ \\
\hline - UTI & $29(17)$ \\
\hline - LUTS & $71(42)$ \\
\hline - trombo-embolie & $1(0,6)$ \\
\hline - anders & $6(3,5)$ \\
\hline fistels, $n$ (\%) & \\
\hline - recto-urethraal/vesicaal & $9(5,3)$ \\
\hline - transcutaan & $2(1,2)$ \\
\hline - beide & $2(1,2)$ \\
\hline overlijden, $n$ (\%) & \\
\hline - aan PCa & $7(4,1)$ \\
\hline - andere oorzaak & $10(5,9)$ \\
\hline IQR interkwartielrange, PCa prostaatkanker, SCS salvage cryochirurgie
\end{tabular}

\section{Kaplan-Meier survival analysis}

\section{Biochemisch-recidiefvrije overleving (Phoenix)}

In totaal ontwikkelden 65 (39\%) patiënten een BR. Ten tijde van de mediane follow-up van 36 maanden (IQR $=18-66)$ was de BRFS (PSA-nadir $+2 \mathrm{ng} / \mathrm{ml}$ ) $58 \%(95 \%-B I=49-67)$. De BRFS na vijf en acht jaar was respectievelijk $52 \%(95 \%-\mathrm{BI}=43-62)$ en $45 \%(95 \%$ $\mathrm{BI}=35-57$ ) (fig. 2). De mediane BRFS was 65 maanden (95\%-BI: 36 - niet bereikt).

Patiënten met pre-sCC $\mathrm{PSA}<10 \mathrm{ng} / \mathrm{ml}$ hadden een 5 -jaars-BRFS van $55 \%(95 \%-\mathrm{BI}=43-76)$ vergeleken met $37 \%(95 \%-\mathrm{BI}=22-62)$ voor patiënten met PSA $\geq 10 \mathrm{ng} / \mathrm{ml}$ (log-rank: $p=0,02$ ) (fig. 3a). Patiënten met een PSA-nadir $\leq 0,1 \mathrm{ng} / \mathrm{ml}$ hadden een 5 -jaarsBRFS van $78 \%(95 \%-\mathrm{BI}=66-91)$ vergeleken met $33 \%$ $(95 \%-\mathrm{BI}=23-48)$ voor patiënten met een PSA-nadir $>0,1 \mathrm{ng} / \mathrm{ml}$ (log-rank: $p<0,001$ ) (fig. 3b; $[7,8]$ ).

De resultaten van de univariabele Cox-regressieanalyse van potentiële voorspellers van BRFS zijn opgenomen in tab. 3. Een hogere PSA ten tijde van de initiële diagnose, een hogere pre-sCC PSA-dichtheid, een hoger pre-sCC PSA-nadir en hogere pre-sCC Gleason-scores ( 7 versus $\leq 6)$ waren geassocieerd met een significant verhoogd risico op BR. Omdat EBRT + ADT het risico op de geanalyseerde uitkomsten significant verhoogde, hebben we ervoor gekozen om de primaire behandeling als correctiefactor op te nemen in het multivariabele model. Omdat het pre-sCC PSA en de pre-sCC PSA-dichtheid sterk waren gecorreleerd, werd PSA weggelaten uit de multivariabele analyse. Bij de multivariabele analyse waren PSA bij initiële diagnose, type initiële behandeling, interval tussen primaire be- handeling en sCC, leeftijd en pre-sCC PSA-nadir significante parameters (tab. 3).

\section{Biochemisch-recidiefvrije overleving (PSA >0,5 ng/ml)} Bij een mediane follow-up van 36 maanden (IQR = 18-66) was de BRFS $32 \%(95 \%-\mathrm{BI}=26-41)$. BRFS na vijf en acht jaar was respectievelijk 30\% (95\%$\mathrm{BI}=23-39)$ en $24 \%(95 \%-\mathrm{BI}=14-40)$. De mediane BRFS was 10 maanden $(95 \%-B I=5-17)$. Zie tab. 1 voor resultaten van de Cox proportional hazards regressieanalyse. Bij multivariabele analyse waren een hoger PSA bij initiële diagnose $(p=0,004)$, een korter tijdsinterval van primaire behandeling tot sCC $(p=0,04)$ en een hoger pre-sCC PSA-nadir $(p=0,001)$ geassocieerd met een verhoogd risico op BR.

\section{Overall survival}

De OS na 5 jaar en 10 jaar was respectievelijk $85 \%$ $(95 \%-\mathrm{BI}=78-94)$ en $77 \%(95 \%-\mathrm{BI}=67-88)$. De mediane OS werd niet bereikt. De OS verschilde significant voor PSA-nadir na sCC, met een 10 -jaars-OS van $90 \%$ $(95 \%-\mathrm{BI}=80-100)$ bij een PSA-nadir $\leq 0,1 \mathrm{ng} / \mathrm{ml}$ versus $66 \%(95 \%-\mathrm{BI}=51-84)$ bij een PSA-nadir $>0,1 \mathrm{ng} / \mathrm{ml}$ (log-rank: $p=0,009$ ).

\section{Metastasevrije overleving}

Bij een mediane follow-up van 36 maanden (IQR= 18-66) was de MFS $72 \%$ (95\%-BI=65-80) (fig. 4). De MFS na vijf en acht jaar was respectievelijk 57\% (95\%-

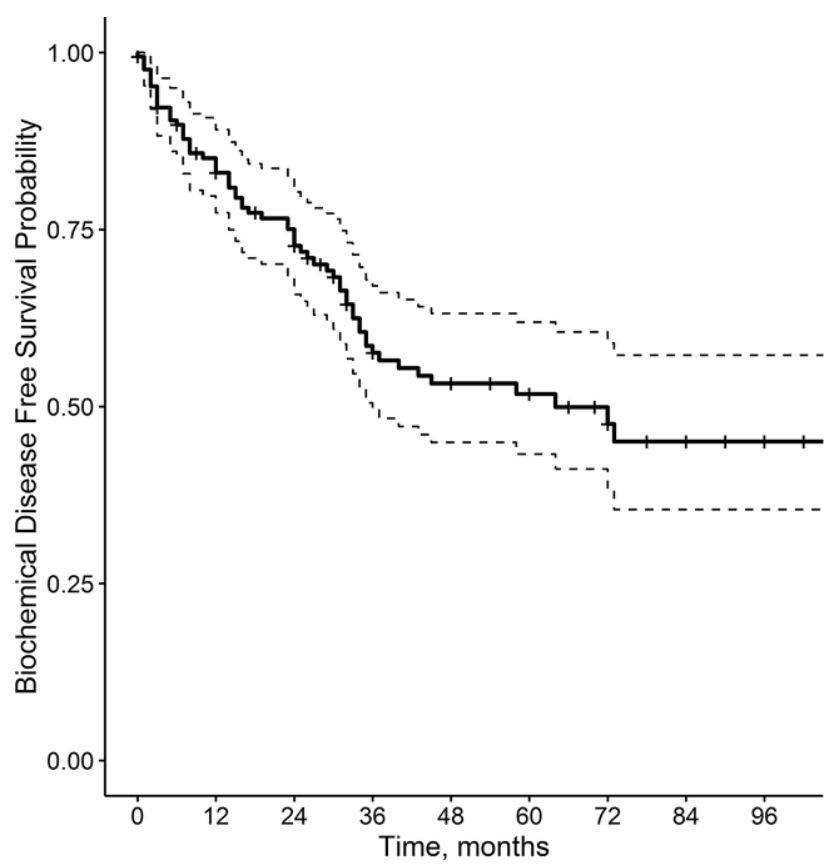

Number at risk

$\begin{array}{lllllllll}169 & 124 & 97 & 60 & 49 & 35 & 21 & 16 & 7\end{array}$

Figuur 2 Kaplan-Meier-curve voor biochemical recurrence free survival (Phoenix) van het hele cohort 

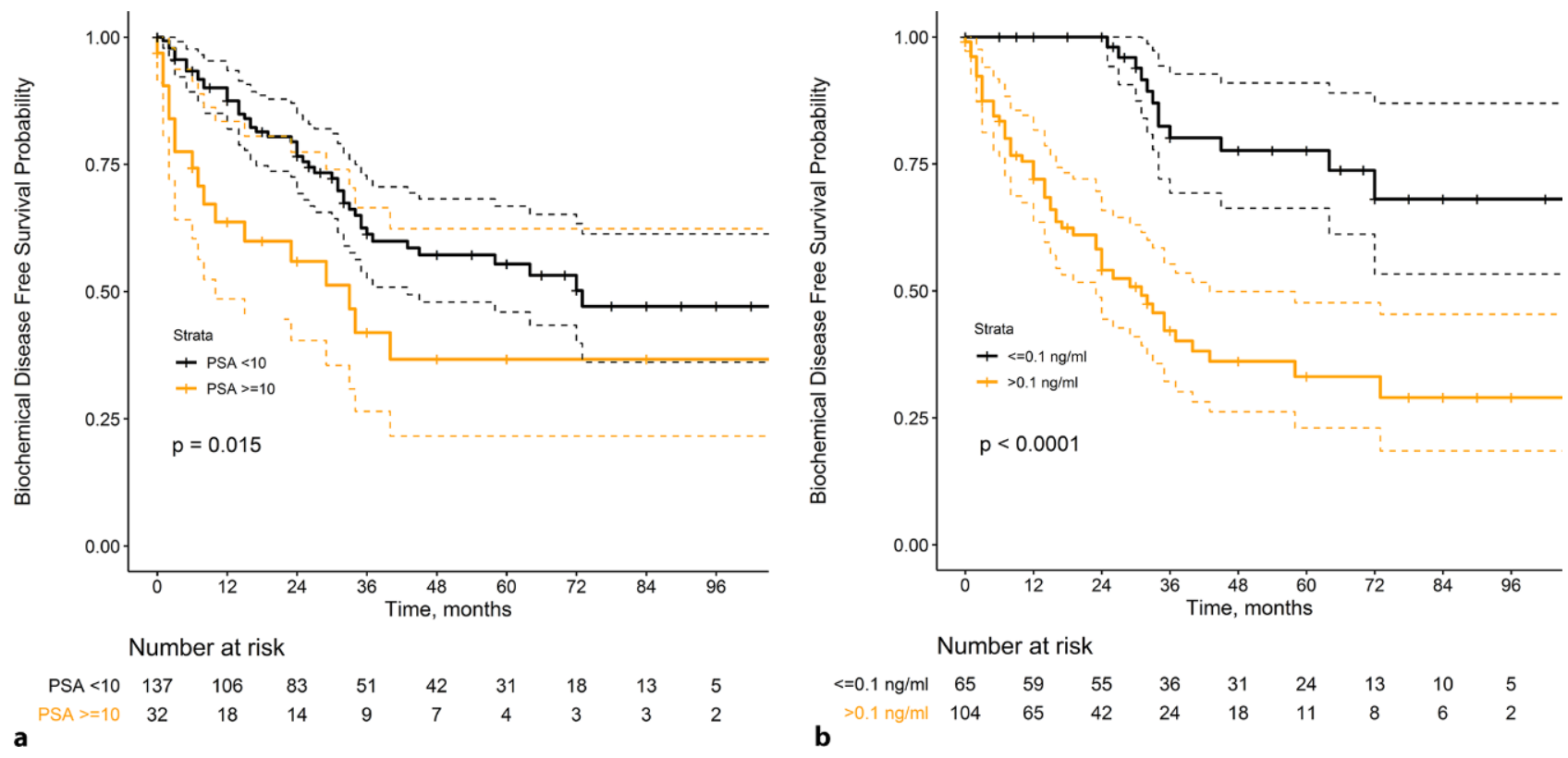

Figuur 3 Het cohort uit fig. 2 gestratificeerd voor a presalvage cryochirurgie PSA en b postsalvage cryochirurgie PSA-nadir

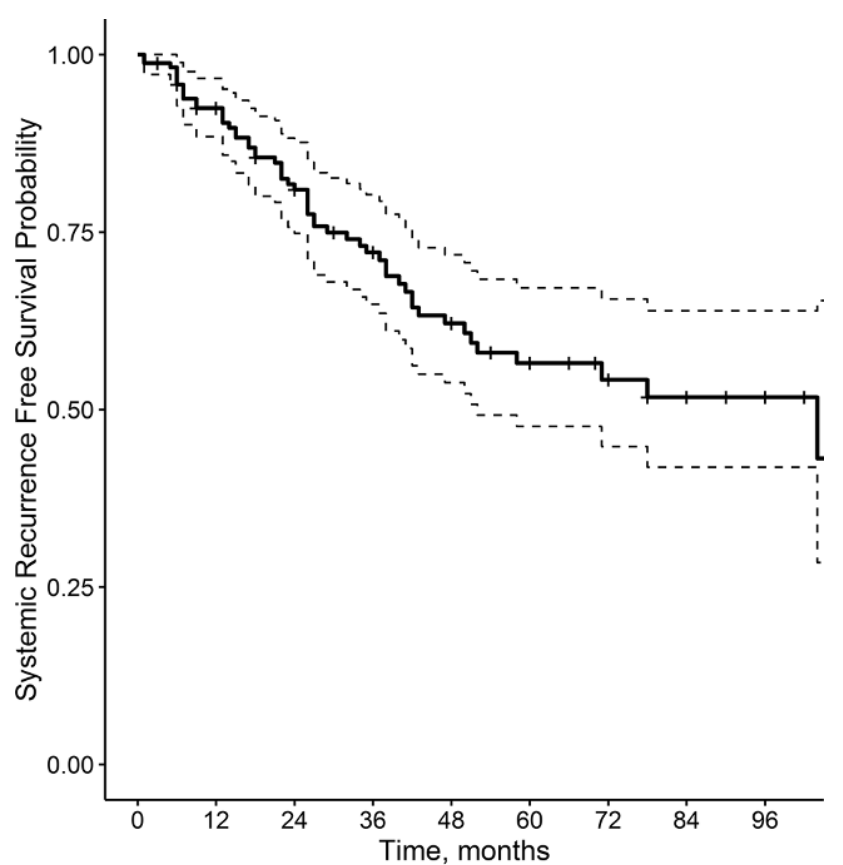

Number at risk

$\begin{array}{lllllllll}169 & 137 & 108 & 77 & 56 & 39 & 23 & 17 & 8\end{array}$

Figuur 4 Kaplan-Meier-curve voor metastasis free survival van het gehele cohort

$\mathrm{BI}=48-67)$ en $52 \%(95 \%-\mathrm{BI}=42-64)$. De mediane MFS was 104 maanden (95\%-BI: 54 - niet bereikt). Zie tab. 2 voor de resultaten van de Cox-regressieanalyse. Bij multivariabele analyse was er een associatie tussen MFS en de initiële behandeling ten gunste van EBRT zonder ADT versus EBRT met ADT $(p<0,001)$, een langer tijdsinterval van initiële behandeling tot sCC $(p=0,007)$, een hogere pre-sCC PSA-dichtheid $(p=0,05)$, het gebruik van pre-sCC PSMA PET/CT $(p<0,001)$, een hogere pre-sCC Gleason-score (7 versus $\leq 6) \quad(p=0,04)$ en een lager pre-sCC PSA-nadir $(p<0,001)$.

\section{ADT-vrije overleving}

Na sCC werd bij 43 (25\%) patiënten gestart met ADT; 36 van deze patiënten hadden een $\mathrm{BR}$ (volgens de Phoenix-criteria). Van de 65 patiënten met een BR begonnen er 36 (55\%) met ADT en 29 (45\%) niet. Van de 104 patiënten zonder BR, hadden er $7(6,7 \%)$ ADT en 97 (93\%) niet. Deze patiënten zonder BR volgens de Phoenix-criteria (maar met BR volgens PSA $>0,5 \mathrm{ng} / \mathrm{ml}$ ) vertoonden echter een snelle toename van PSA (dit is: een korte verdubbelingstijd) en beeldvorming was verdacht voor recidief.

Bij een mediane follow-up van 36 maanden (IQR= 18-66) was de ADT-vrije overleving 80\% (95\%-BI= 73-87). Van degenen die met ADT begonnen, was de mediane tijd waarop met ADT werd gestart 26 maanden $(\mathrm{IQR}=15-41)$. ADT-vrije overleving na vijf en acht jaar was respectievelijk $70 \%(95 \%-\mathrm{BI}=62-79)$ en $57 \%(95 \%-B I=47-70)$. Patiënten met en zonder een pre-sCC PSA-nadir $\leq 0,1 \mathrm{ng} / \mathrm{ml}$ hadden een ADT-vrije overleving van 5 jaar van respectievelijk $81 \%(95 \%-$ $\mathrm{BI}=70-94)$ en $62 \%(95 \%-\mathrm{BI}=52-75$; log rank: $p<0,01)$. Zie tab. 3 voor resultaten van de Cox proportional hazards regressieanalyse. $\mathrm{Bij}$ multivariabele analyse waren de pre-sCC PSA-nadir $(p<0,001)$, de leeftijd $(p=0,009)$ en de primaire behandeling ten gunste van EBRT zonder (neo)adjuvante ADT versus EBRT met (neo)adjuvante ADT ( $p=0,01)$ geassocieerd met ADTvrije overleving.

Met regressiemodellen waarin de initiële Gleasonscore en het T-stadium in plaats van de D'Amico-risi- 
Tabel 3 Univariabele en multivariabele Cox-proportional hazards regressieanalyse voor biochemisch recidief (Phoenix)

\begin{tabular}{|c|c|c|c|c|}
\hline \multirow[t]{2}{*}{ factor } & \multicolumn{2}{|c|}{ univariabele analyse } & \multicolumn{2}{|c|}{ multivariabele analyse } \\
\hline & HR $(95 \%-B I)$ & $p$-waarde & HR (95\%-BI) & $p$-waarde \\
\hline primaire PSA-waarde & $\begin{array}{l}1,01 \\
(1,00-1,02)\end{array}$ & 0,02 & $\begin{array}{l}1,01 \\
(1,00-1,03)\end{array}$ & 0,03 \\
\hline \multicolumn{5}{|l|}{ primair T-stadium } \\
\hline-2 vs. 1 & $\begin{array}{l}1,45 \\
(0,69-3,01)\end{array}$ & 0,32 & & \\
\hline$-3-4$ vs. 1 & $\begin{array}{l}1,33 \\
(0,67-2,64)\end{array}$ & 0,42 & & \\
\hline \multicolumn{5}{|l|}{ primaire Gleason-score } \\
\hline-7 vs. $\leq 6$ & $\begin{array}{l}0,94 \\
(0,52-1,72)\end{array}$ & 0,85 & & \\
\hline$-8-10$ vs. $\leq 6$ & $\begin{array}{l}0,89 \\
(0,46-1,75)\end{array}$ & 0,74 & & \\
\hline \multicolumn{5}{|l|}{$\begin{array}{l}\text { primaire d'Amico risico- } \\
\text { groep }\end{array}$} \\
\hline-2 vs. 1 & $\begin{array}{l}1,35 \\
(0,50-3,60)\end{array}$ & 0,55 & $\begin{array}{l}1,52 \\
(0,41-5,65)\end{array}$ & 0,53 \\
\hline-3 vs. 1 & $\begin{array}{l}1,54 \\
(0,64-3,71)\end{array}$ & 0,34 & $\begin{array}{l}1,38 \\
(0,36-5,28)\end{array}$ & 0,64 \\
\hline \multicolumn{5}{|l|}{ primaire behandeling } \\
\hline $\begin{array}{l}\text { - EBRT + ADT vs. enkel } \\
\text { EBRT }\end{array}$ & $\begin{array}{l}1,74 \\
(1,00-3,05)\end{array}$ & 0,05 & $\begin{array}{l}2,33 \\
(1,12-4,87)\end{array}$ & 0,02 \\
\hline $\begin{array}{l}\text { - brachytherapie vs. } \\
\text { enkel EBRT }\end{array}$ & $\begin{array}{l}1,47 \\
(0,70-3,10)\end{array}$ & 0,31 & $\begin{array}{l}2,45 \\
(1,05-5,71)\end{array}$ & 0,04 \\
\hline $\begin{array}{l}\text { interval primaire therapie } \\
\text { en SCS }\end{array}$ & $\begin{array}{l}0,92 \\
(0,83-1,01)\end{array}$ & 0,09 & $\begin{array}{l}0,87 \\
(0,78-0,99)\end{array}$ & 0,03 \\
\hline leeftijd bij SCS & $\begin{array}{l}1,03 \\
(0,99-1,08)\end{array}$ & 0,17 & $\begin{array}{l}1,07 \\
(1,02-1,13)\end{array}$ & 0,005 \\
\hline pre-SCS PSA & $\begin{array}{l}1,01 \\
(1,00-1,02)\end{array}$ & 0,10 & & \\
\hline pre-SCS prostate volume & $\begin{array}{l}1,00 \\
(0,97-1,02)\end{array}$ & 0,75 & & \\
\hline pre-SCS PSA-density & $\begin{array}{l}1,43 \\
(1,01-2,03)\end{array}$ & 0,04 & $\begin{array}{l}1,51 \\
(0,91-2,51)\end{array}$ & 0,11 \\
\hline post-SCS PSA-nadir & $\begin{array}{l}1,09 \\
(1,06-1,11)\end{array}$ & $<0,001$ & $\begin{array}{l}1,11 \\
(1,07-1,15)\end{array}$ & $<0,001$ \\
\hline tijd tot PSA-nadir & $\begin{array}{l}0,99 \\
(0,90-1,10)\end{array}$ & 0,90 & & \\
\hline pre-SCS MRI, ja of nee & $\begin{array}{l}0,80 \\
(0,43-1,50)\end{array}$ & 0,49 & & \\
\hline $\begin{array}{l}\text { pre-SCS PSMA PET/CT, ja } \\
\text { of nee }\end{array}$ & $\begin{array}{l}0,83 \\
(0,20-3,49)\end{array}$ & 0,80 & & \\
\hline \multicolumn{5}{|l|}{ pre-SCS Gleason-score } \\
\hline-7 vs. $\leq 6$ & $\begin{array}{l}1,74 \\
(1,00-3,05)\end{array}$ & 0,05 & $\begin{array}{l}0,78 \\
(0,38-1,61)\end{array}$ & 0,50 \\
\hline$-8-10$ vs. $\leq 6$ & $\begin{array}{l}1,47 \\
(0,70-1,30)\end{array}$ & 0,31 & $\begin{array}{l}0,57 \\
(0,26-1,24)\end{array}$ & 0,16 \\
\hline
\end{tabular}

$A D T$ androgeendeprivatietherapie, EBRT external beam radiotherapy, $H R$ hazard ratio, SCS salvage cryochirurgie

cogroepen waren opgenomen, leidden deze risicofactoren niet tot significante uitkomsten.

\section{Biopsie}

Na sCC ondergingen 21 (12\%) patiënten een biopsie, die alle positief waren. $12 / 21(57 \%)$ patiënten die een biopsie ondergingen, hadden een BR volgens de Phoenix-criteria. Alle biopsiepatiënten hadden een PSA $>0,5 \mathrm{ng} / \mathrm{ml}$ (secundaire uitkomst).

\section{Toxiciteit}

\section{Complicaties op korte termijn}

Er waren geen sterfgevallen als gevolg van de procedure. Complicaties van graad I, II en IIIa binnen 30 dagen na de behandeling traden op bij respectievelijk $71(42 \%), 31(18 \%)$ en $2(1,2 \%)$ patiënten (1 fistel en 1 acute appendicitis). De meest voorkomende complicaties waren hematurie (18\%), urineweginfecties $(17 \%)$ en LUTS, waarvoor medische behandeling nodig was (33\%) (tab. 2).

\section{Functionele resultaten}

Bij 20 (12\%) patiënten was desobstructie nodig vanwege urethral sloughing en/of stenose binnen 12 maanden na sCC. Desobstructie bestond bij 17 patiënten uit een transurethrale resectie van de prostaat en bij drie patiënten uit een urethrotomie.

Bij alle patiënten waren de pre-sCC continentiestatus en de pre-sCC erectiefunctie bekend. 13/169 $(7,7 \%)$ patiënten hadden enige vorm van pre-existente urine-incontinentie en bij 29/156 patiënten (19\%) ontstond new-onset urine-incontinentie, waarvan $10(6,4 \%)$ twee tot drie pads/24 uur en 19 (12\%) patiënten $>$ drie pads/24 uur nodig hadden. De cumulatieve incidentie van urine-incontinentie nam in de loop van de tijd af (fig. 5a).

Bij 107/169 (63\%) patiënten was er sprake van presCC ED; bij 57/62 (92\%) patiënten van new-onset ED, van wie $53(85 \%)$ patiënten een volledig verlies van erectiele functie hadden. Vier patiënten $(6,5 \%)$ ondervonden verbetering van erectiele functie met ofwel papaverine/fentolamine-injecties of een PDE-5-remmer.

\section{Fistels}

Negen patiënten $(5,3 \%)$ ontwikkelden een persisterende recto-urethrale of rectovesicale fistel, twee patiënten $(1,2 \%)$ hadden een cutane fistel en twee $(1,2 \%)$ patiënten hadden beide, allen $<24$ maanden na sCC (mediaan 6 maanden, IQR=3-9) (tab. 2). De cumulatieve incidentie van fistels nam in de loop van de tijd af (fig. 5b). Daarnaast werd er geen significant verschil in persisterende fistelvorming tussen de twee behandelgroepen gevonden (van de patiënten na brachytherapie ontwikkelde $3,2 \%(1 / 31)$ een fistel, versus $7,2 \%$ $(10 / 138)$ van de patiënten na EBRT, $p=0,41)$. Van de 11 patiënten met een persisterende urinaire fistel, kregen er twee een colostoma en nefrostomiekatheters, twee kregen een suprapubische katheter als eindoplossing, vijf ondergingen een cystoprostatectomie met een Bricker-deviatie en twee ondergingen een gracilisplastiek om de fistel te corrigeren. 

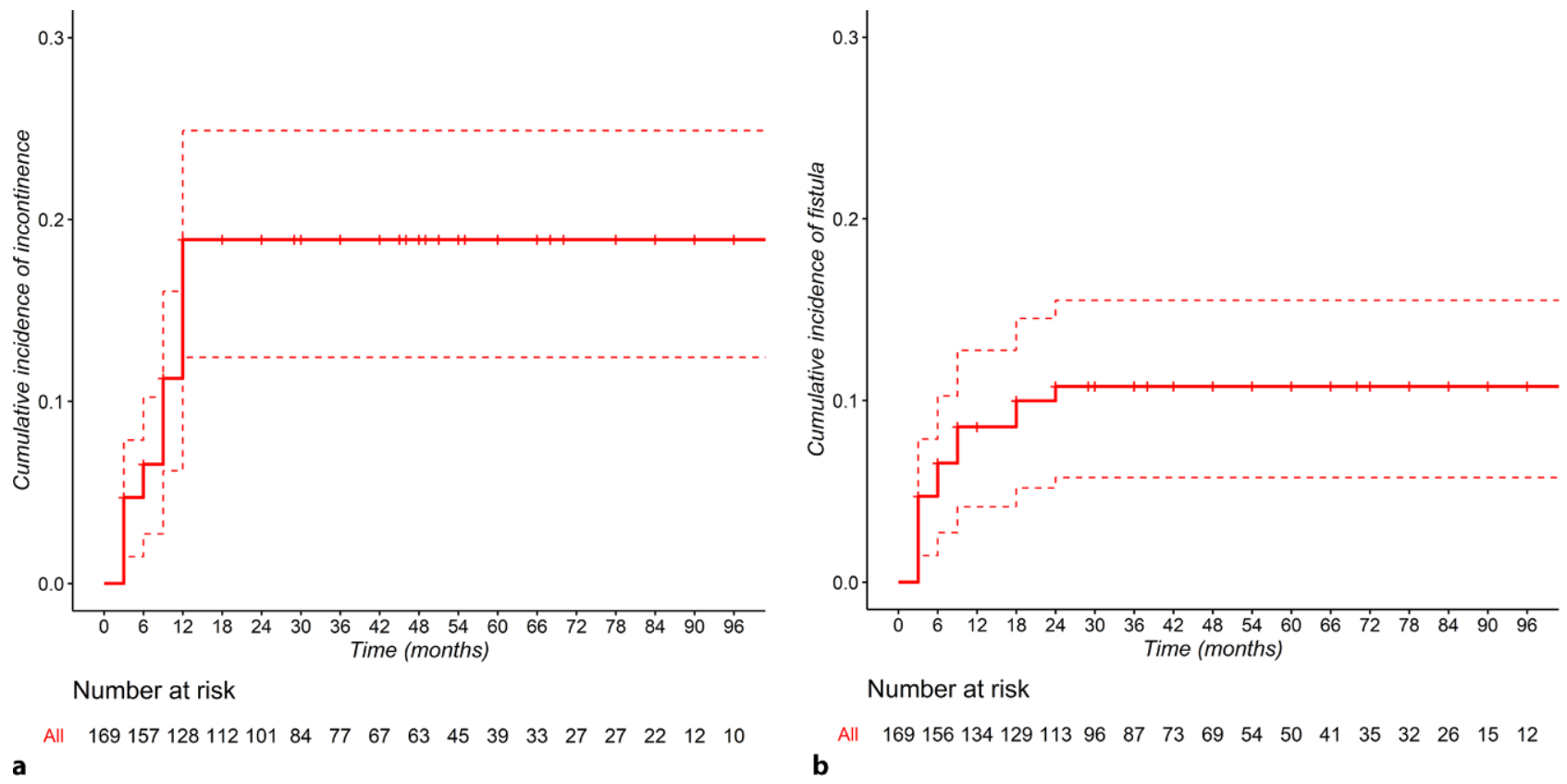

Figuur 5 Plot van de cumulatieve incidentie van complicaties. a Nieuw ontstane urine-incontinentie. b Fistels

\section{Behandeling van de volledige prostaat versus hemi- ablatie}

154 patiënten $(91 \%)$ ondergingen sCC van de volledige prostaat en 15 patiënten $(8,9 \%)$ hemi-ablatie op basis van pre-sCC beeldvorming en biopsie. Er werd geen significant verschil tussen de groepen gezien voor het ontstaan van fistels (resp. 6,5\% vs. 6,7\%; $p=0,98$ ), new-onset ED (resp. 33\% vs. 40\%; $p=0,59$ ) of van new-onset UI (resp. $19 \%$ vs. $0,0 \%$; $p=0,07$ ).

Bij univariabele Cox-regressieanalyse was de mate van ablatie (hemi vs. volledige) geen significant voorspellende factor voor BRFS volgens de Phoenix-definitie $(\mathrm{HR}=0,48 ; 95 \%-\mathrm{BI}=0,12-1,97 ; p=0,31)$ of voor andere oncologische uitkomsten.

\section{Discussie}

Hoewel watchful waiting en ADT in opzet niet curatief zijn, worden patiënten met een lokaal rrPCa dikwijls op een van deze wijzen behandeld. ADT heeft echter slechts tijdelijk effect en daarnaast is deze behandeling geassocieerd met een verminderde kwaliteit van leven (QoL). Salvage prostatectomie is een potentieel curatieve behandelingsoptie, maar een technisch uitdagende procedure na radiotherapie door fibrosering en deze behandeling is bovendien geassocieerd met ernstige bijwerkingen [9].

Ablatieve technieken, zoals cryochirurgie, HIFU en brachytherapie zijn ontwikkeld om de kanker lokaal onder controle te krijgen en morbiditeit te minimaliseren. Een recente systematische review door Ingrosso et al. [10] laat veelbelovende uitkomsten zien van deze niet-chirurgische behandelingen, hoewel er geen conclusies met sterk bewijs konden worden ge- trokken. Men moet erop bedacht zijn dat veel studies over sCC afkomstig zijn uit dezelfde expertisecentra. Dit kan leiden tot publicatiebias van positieve studies door overlappende resultaten [11]. Studies naar middellange- tot langetermijn functionele en oncologische uitkomsten van sCC waarin $>50$ patiënten zijn geïncludeerd zijn schaars. Daarom draagt onze studie bij aan de kennis van de rol van sCC voor rrPCa, hoewel er prospectieve cohortstudies nodig zijn om krachtiger bewijs te verkrijgen. Het uitvoeren van cryochirurgie vereist voldoende ervaring en vaardigheden, en onze studie toont het belang aan van de leercurve en adequate training.

\section{Selectie van patiënten}

Spiess et al. [12] hebben een pre-behandelingsnomogram ontwikkeld voor de selectie van sCC-patiënten dat is gebaseerd op PSA, Gleason-score en klinisch stadium bij initiële diagnose, waarmee de kans op BR in een multi-institutionele analyse van 797 patiënten kon worden voorspeld. Ook andere studies tonen het belang aan van verschillende parameters ten tijde van de initiële diagnose respectievelijk pre-sCC voor het voorspellen van BRFS [7, 13]. Significant voorspellende factoren voor BRFS in onze studie waren de PSA-waarde bij initiële diagnose, het type van de initiële behandeling, de leeftijd, het interval tussen de initiële behandeling en sCC en post-sCC PSA-nadir. We hebben ook bevestigd dat patiënten met een pre-sCC PSA-waarde van > $10 \mathrm{ng} / \mathrm{ml}$ slechtere uitkomsten hebben dan patiënten met een PSA-waarde van $<10 \mathrm{ng} / \mathrm{ml}$ [14-16]. Deze bevinding benadrukt het belang van tijdige diagnose van patiënten met rrPCa. 
Patiënten die eerder met ADT zijn behandeld, worden vaak geëxcludeerd voor sCC [14]. Li et al. [17] toonden aan dat patiënten met pre-sCC ADT een inferieure 5-jaars-BRFS hadden (Phoenix-definitie) in vergelijking met ADT-naïeve patiënten (64\% vs. 39\%; $p<0,0001)$. Dit werd ook waargenomen in onze studie. Hoewel, evenals in andere studies, post-sCC PSAnadir een sterke voorspeller van BRFS was, is deze parameter niet bruikbaar gebleken voor patiëntselectie; deze nadir kan echter de follow-up ondersteunen als aanwijzing voor het intensiveren van ADT-monitoring en/of het starten met ADT [13, 18].

Omdat alleen patiënten met een lokaal recidief potentieel genezen kunnen worden door middel van sCC, is het van groot belang om eventuele (occulte) metastasen zo zeker mogelijk uit te sluiten. Hoewel een pelviene lymfeklierdissectie (PLND) een optie is, wordt voor patiëntselectie niet-invasieve beeldvorming geprefereerd. PSMA PET/CT wordt in onze kliniek routinematig toegepast om systemische ziekte uit te sluiten al vanaf het moment dat deze techniek beschikbaar was. Interessant genoeg vonden we dat de toepassing van PSMA PET/CT zowel in uni- als in multivariabele Coxregressieanalyses een voorspellende factor is voor systemisch recidief. De basiskarakteristieken van patiënten die een PSMA PET/CT ondergaan of juist niet, verschillen niet significant. Dat de PSMA PET/CT-scan voorspellend is voor chemisch recidief representeert dan ook waarschijnlijk meer het 'PSMA PET/CT-tijdperk' zelf, dan de techniek zelf. De meeste patiënten die een PSMA PET/CT-scan ondergingen tijdens pre-sCC-evaluatie kregen bij een stijgend PSA namelijk ook een postsCC PSMA PET/CT-scan (in plaats van een CT- en/of een botscan). Dat is dan wellicht de reden dat een systemisch recidief bij hen eerder is vastgesteld dan bij patiënten van voor het 'PSMA PET/CT-tijdperk'. Het aantal patiënten dat echter een pre-sCC PSMA PET/CT-scan kreeg $(n=18)$ was beperkt, wat het lastig maakt om solide conclusies te trekken. Anderzijds is het niet onaannemelijk dat routinematige toepassing van pre-sCC PSMA PET/CT-onderzoek leidt tot een betere patiëntenselectie en dientengevolge tot een hogere BRFS.

\section{Oncologische uitkomsten}

Oncologische uitkomsten van salvagetherapie worden bepaald door het risicoprofiel van de patiënt, definities van BR en de duur van follow-up. Volgens de aanbevelingen van de AUA Best Practice Statement zijn de oncologische uitkomsten na sCC gebaseerd op de afwezigheid van persisterende ziekte bij biopsie of een PSA-waarde van $<0,5 \mathrm{ng} / \mathrm{ml}$ [19]. Wij hebben geen routinematige post-sCC-biopsie uitgevoerd om invasieve procedures te voorkomen en gebruikten BRFS als een surrogaateindpunt, zoals in veel andere studies. Jammer genoeg worden in de diverse studies verschillende definities van BRFS gebruikt, wat het lastig maakt om de data onderling te vergelijken. Het meest gebruikte eindpunt voor sCC is de Phoenix-definitie (PSA-nadir $+2 \mathrm{ng} / \mathrm{ml}$ ), oorspronkelijk ontwikkeld door de Radiation Therapy Oncology (RTOG)-American Society for Therapeutic Radiology and Oncology (ASTRO) Phoenix Consensus Conference met als doel rrPCa te definiëren [20]. Omdat de mechanismen van celdood na RT en cryochirurgie echter verschillen, kan het zijn dat deze definitie strikt genomen niet valide is voor toepassing op sCC. PSA-cut-offwaarden $<0,5 \mathrm{ng} / \mathrm{ml}$ of $<1,0 \mathrm{ng} / \mathrm{ml}$ zijn mogelijk betere parameters om BRFS na sCC mee te definiëren, omdat verschillende studies suggereren dat deze cut-offwaarden de beste objectieve voorspellers zijn voor biochemische controle $[13,15,18]$. Daarom is in deze studie als secundaire uitkomstmaat BRFS ook geanalyseerd met toepassing van een cut-off van $>0,5 \mathrm{ng} / \mathrm{ml}$.

In hedendaagse sCC-studies varieert de BRFS tussen de 20 en 87,4\%. [14] Pisters et al. [16] definieerden een BR als een PSA-nadir van $>0,4 \mathrm{ng} / \mathrm{ml}$ of elke PSA-stijging na het bereiken van deze waarde en vonden op grond van deze definitie een 5-jaarsBRFS van $21 \%$. Wordt echter de Phoenix-definitie gebruikt, dan varieert de 5-jaars-BRFS tussen de 45 en $64 \%$. Deze percentages zijn vergelijkbaar met onze resultaten (BRFS van 52\%) en komen overeen met de bevindingen in de literatuur na salvage prostatectomie [7, 13, 16, 17], HIFU (5-jaars-BRFS 52,72\% (95\%$\mathrm{BI}=42,66-62,56)$ ) en HDR brachytherapie (5-jaarsBRFS 60\% (95\%-BI=52-67)) [21].

Voor het betrouwbaar informeren van patiënten over de oncologische uitkomsten van sCC schieten surrogaat eindpunten zoals BRFS-percentages tekort, terwijl tegelijkertijd het bereiken van eindpunten zoals OS of ziektespecifieke overleving te lang duurt. Zeker bij de ouder wordende patiënt hoeft een stijgende PSA-waarde niet klinisch-relevant te zijn. Omdat ADT is geassocieerd met cardiovasculaire morbiditeit en een verminderde kwaliteit van leven, kan het succesvol uitstellen van ADT na sCC ook beschouwd worden als een gewenste uitkomst [22]. In ons huidige cohort wordt deze gedachte ondersteund door de observatie dat op verschillende tijdspunten de ADT-vrije overleving groter is dan MFS. Dit kan verklaard worden door het feit dat er bij oudere asymptomatische patiënten met comorbiditeit watchful waiting is toegepast in plaats van dat met ADT is gestart. Onze data laten zien dat bij ongeveer $75 \%$ van de patiënten ADT vermeden kan worden. De 5-jaars-ADT-vrije overleving was $70 \%$, wat overeenkomt met eerder gepubliceerde data $[7,23]$.

\section{Functionele uitkomsten en toxiciteit}

Salvageprocedures worden geassocieerd met een hogere morbiditeit dan primaire behandelingen [24]. In een eerdere studie trad na sCC bij $73 \%$ van de patiënten UI op, maar met de derdegeneratie-sCC zijn de complicaties afgenomen $[11,16]$. Toch blijven be- 
denkingen over toxiciteit en met name UI en fistelvorming belemmerende factoren.

In onze huidige studie kwam nieuw ontstane UI voor bij $19 \%$ van de patiënten. Recente studies beschrijven UI bij 12-48\% van de patiënten, afhankelijk van de definitie van UI. Ter vergelijking: salvage prostatectomie leidt in 30-72\% van de gevallen tot UI [14]. Sfincterbeschadiging is gerelateerd aan de lengte van de ijsbal, en die lengte is weer afhankelijk van het soort cryonaald dat gebruikt wordt. Deze lengte kan tijdens de procedure niet worden aangepast. Daardoor kan sfincterschade alleen worden geminimaliseerd door de positie van de naald te veranderen en/of de vriestijd te verkorten.

$\mathrm{Na}$ sCC heeft een groot aantal patiënten ED (60-100\%), maar veel patiënten hadden pre-existente ED als gevolg van de eerder ondergane radiotherapie, zoals ook blijkt uit onze huidige studie [14]. Nieuw ontstane ED na sCC herstelt slechts bij een enkele patiënt. De ernstigste complicatie na sCC is fistelvorming, wat ernstige morbiditeit tot gevolg kan hebben. Dat bij ons sprake was van onmiskenbaar hoge percentages fistelvorming heeft mogelijk een aantal redenen. Allereerst, kwam fistelvorming minder vaak voor nadat de procedure al langere tijd door de operateur werd verricht, wat suggestief is voor een leercurve van de procedure. In dit verband is het opmerkelijk dat Cohen [25] beschreef dat de meeste fistels ontstaan bij de eerste 25 patiënten die behandeld werden met sCC. Het uitvoeren van sCC vereist een voorzichtig balanceren tussen veiligheid en effectiviteit. Te veel focus op effectiviteit brengt de veiligheid in gevaar en omgekeerd kan het focussen op veiligheid de oncologische uitkomst in negatieve zin beïnvloeden. Met goede oncologische uitkomsten voor ogen vond bij een aantal patiënten het bevriezen mogelijk te agressief plaats, met name in het geval van grote tumoren, waarbij de ijsbal zich uitbreidde tot buiten het prostaatkapsel. Het hoge risico op toxiciteit heeft geleid tot een strengere patiëntselectie en minder agressief bevriezen. Daarnaast zijn er ook maatregelen genomen om het risico van rectumschade te minimaliseren door extra naalden in de rectumwand te plaatsen voor active warming [26, 27]. Daarnaast kan het risico op fistelvorming zijn verminderd doordat de techniek die bij radiotherapie wordt gebruikt, is verbeterd en de doseringen zijn aangepast.

Als laatste de follow-up: wij hebben ervaren dat het uitdagend is om goede follow-up te bereiken bij alle patiënten, vooral wanneer ze terugkeren naar hun verwijzende centra. Het is dus niet ondenkbaar dat er in meerdere studies, door ontbrekende follow-updata, sprake is van onderrapportage van data over toxiciteit.

Focale/hemi-ablatie heeft als doel het risico van ernstige toxiciteit te verminderen doordat deze benadering alleen op de tumor zelf is gericht. Het sparen van blootstelling aan bevriezing van het omliggende gezonde weefsel kan zowel de oncologische als de functionele uitkomsten beïnvloeden. Vooral recent is er toenemende interesse in deze benadering. Studies die de uitkomsten van focale sCC/hemi-ablatie onderzoeken, suggereren een 5-jaars-BRFS die vergelijkbaar is met de uitkomsten van studies die het behandelen van de hele prostaat onderzoeken (ca. 50\%) $[17,28,29]$. Het is echter nog niet aangetoond dat focale sCC is geassocieerd met een significante verbetering van de morbiditeitspercentages [17, 28, 29]. Grotere studies met langere follow-upduur zijn nodig om de rol van focale salvagetherapie te verduidelijken.

In onze studie is er alleen hemi-ablatie uitgevoerd bij patiënten met gunstige klinische karakteristieken, maar deze groep was relatief klein. Om deze reden zijn de data van whole gland en hemi-ablatie gecombineerd. Toch hebben we de functionele en oncologische resultaten van patiënten die hemi-ablatie ondergingen apart beschreven. Hoewel niet statistisch-significant, ontstond behandelingsgerelateerde nieuw-ontstane UI minder vaak bij partiële ablatie vergeleken dan bij whole-gland-ablatie. We vonden geen significante fistelvorming en nieuw-ontstane ED tussen beide groepen. Echter, het aantal patiënten dat partiële ablatie onderging, was gering $(n=15)$. Mogelijk zullen analyses van toekomstige studies met grotere patiëntcohorten betere uitkomsten laten zien.

Goede patiëntselectie is zeer belangrijk wanneer hemi-ablatie wordt toegepast en grote voorzichtigheid is geboden, omdat er sprake kan zijn van occulte multifocaliteit. In onze studie werden MRI (en meer recent PSMA PET/CT) gebruikt om rrPCa te detecteren en te lokaliseren. Ondanks de hoge negatief-voorspellende waarden op mpMRI voor de detectie van lokale recidieven, kan beeldvorming tumoren hebben gemist [30]. Daarom werden alleen patiënten met unilaterale laagvolumerecidieven op de mpMRI (en meer recent ook op PSMA PET/CT)-scans, samen met negatieve contralaterale biopsies geschikt geacht voor hemi-ablatie.

\section{Beperkingen}

De huidige studie heeft een aantal beperkingen. Het is een retrospectieve studie, en van sommige patiënten ontbraken data over toxiciteit. Voor oncologische uitkomsten zijn meerdere imputaties gebruikt ter correctie van deze ontbrekende data. Om op een objectieve manier functionele uitkomsten te kunnen bepalen zijn bij aanvang van de studie gekwalificeerde vragenlijsten gebruikt (zoals de IPSS en de Sexual Health Inventory for men (SHIM)). Deze vragenlijsten werden echter onvoldoende consistent ingevuld, wat resulteerde in onvoldoende data om solide conclusies uit te trekken. Om maximalisatie van de beschikbare uitkomst te bewerkstelligen, moesten we terugvallen op mondelinge door de patiënt gerapporteerde uitkomsten, zoals die gedocumenteerd waren bij followupbezoeken, maar we zijn ons bewust van de beperkingen hiervan. Ten tweede is de studie uitgevoerd in 
een enkel centrum. Dit kan een beperking zijn. Aan de andere kant verschaft longitudinale follow-up na een uniforme sCC-procedure inzicht in de klinische praktijk van een verwijzingscentrum en de cumulatieve leercurve van de procedure. Ten derde zijn wij niet in staat om te bewijzen dat sCC voordelen heeft ten opzichte van andere salvage behandelingsopties, omdat een controlegroep ontbreekt. Tot slot vond geen routinematige post-sCC histologische verificatie van de effectiviteit van de behandeling plaats.

Het vergelijken van onze studieresultaten met die van andere huidige studies naar sCC wordt beperkt door variaties in de steekproefgrootte, duur van de follow-up en definities van BR. Desondanks beschouwen wij onze data als een betrouwbare en transparante basis voor de counseling van patiënten in ons instituut met betrekking tot sCC, omdat de data de reflectie is van single-institution experience.

\section{Conclusie}

De uitkomsten van onze studie tonen aan dat, in afwezigheid van een standaardbehandeling voor $\mathrm{rrCC}$, sCC uitgevoerd kan worden met goede oncologische uitkomsten op de middellange termijn, het salvagekarakter van de behandeling in acht nemend. Echter, het optreden van significante complicaties, zoals UI, fistelvorming en stenose moet niet onderschat worden. Voor een accurate patiëntselectie moet rekening gehouden worden met zowel de individuele voorkeuren van de patiënt als met pre-sCC-karakteristieken.

Open Access This article is distributed under the terms of the Creative Commons Attribution 4.0 International License (http://creativecommons.org/licenses/by/4.0/), which permits unrestricted use, distribution, and reproduction in any medium, provided you give appropriate credit to the original author(s) and the source, provide a link to the Creative Commons license, and indicate if changes were made.

\section{Literatuur}

1. Agarwal PK, Sadetsky N, Konety BR, Resnick MI, Carroll PR. Treatment failure after primary and salvage therapy for prostate cancer: likelihood, patterns of care, and outcomes. Cancer. 2008;112(2):307-14.

2. Cary KC, Paciorek A, Fuldeore MJ, Carroll PR, Cooperberg MR. Temporal trends and predictors of salvage cancer treatment after failure following radical prostatectomy or radiation therapy: an analysis from the CaPSURE registry. Cancer. 2014;120(4):507-12.

3. Tran H, Kwok J, Pickles T, Tyldesley S, Black PC. Underutilization of local salvage therapy after radiation therapy for prostate cancer. UrolOncol. 2014;32(5):701-6.

4. D'Amico AV, Whittington R, Malkowicz SB, et al. Biochemical outcome after radical prostatectomy, external beam radiation therapy, or interstitial radiation therapy for clinicallylocalized prostate cancer. JAMA. 1998;280(11):969-74.

5. Dindo D, Demartines N, Clavien PA. Classification of surgical complications: a new proposal with evaluation in a cohort of 6336 patients and results of a survey. Ann Surg. 2004;240(2):205-13.
6. Peduzzi P, Concato J, Feinstein AR, Holford TR. Importance of events per independent variable in proportional hazards regression analysis. II. Accuracy and precision of regression estimates. JClin Epidemiol. 1995;48(12):1503-10.

7. Williams AK, Martínez CH, Lu C, Ng CK, Pautler SE, Chin JL. Disease-free survival following salvage cryotherapy for biopsy-proven radio-recurrent prostate cancer. Eur Urol. 2011;60(3):405-10.

8. Nyame YA, Elshafei A, Greene DJ, et al. Prostate specific antigen nadir of 0.1 or less is a predictor of treatment success in men undergoing salvage whole prostate gland cryoablation. JEndourol. 2017;31(5):497-501.

9. Chade DC, Eastham J, Graefen M, et al. Cancer control and functional outcomes of salvage radical prostatectomy for radiation-recurrent prostate cancer: a systematic review of the literature. Eur Urol. 2012;61(5):961-71.

10. Ingrosso $G$, Becherini C, Lancia A, et al. Nonsurgical salvage local therapies for radiorecurrent prostate cancer: a systematic review and meta-analysis. Eur Urol Oncol. 2020;3(2):183-97.

11. Langenhuijsen JF, Broers EMP, Vergunst H. Cryosurgery for prostate cancer: an update on clinical results of modern cryotechnology. Eur Urol. 2009;55(1):76-86.

12. Spiess PE, Katz AE, Chin JL, et al. A pretreatment nomogram predicting biochemical failure after salvage cryotherapy for locally recurrent prostate cancer. BJU Int. 2010;106(2):194-8.

13. Siddiqui KM, Billia M, Al-Zahrani A, et al. Long-term oncologic outcomes of salvage cryoablation for radio-recurrent prostate cancer. J Urol. 2016;196(4):1105-11.

14. Golbari NM, Katz AE. Salvage therapy options for local prostate cancer recurrence after primary radiotherapy: aliterature review. Curr Urol Rep. 2017;18(8):63.

15. Ahmad I, Kalna G, Ismail M, et al. Prostate gland lengths and iceball dimensions predict micturition functional outcome following salvage prostate cryotherapy in men with radiation recurrent prostate cancer. Plos One. 2013;8(8):e69243.

16. Pisters LL, Leibovici D, Blute M, et al. Locally recurrent prostatecancer after initial radiation therapy: acomparison of salvage radical prostatectomy versus cryotherapy. J Urol. 2009;182(2):517-25. discussion 25-7.

17. Li R, Ruckle HC, Schlaifer AE, El-Shafei A, Yu C, Jones JS. The effect of androgen deprivation therapy before salvage whole-gland cryoablation after primary radiation failure in prostate cancer treatment. Urology. 2015;85(5):1137-42.

18. Kovac E, ElShafei A, Tay KJ, Mendez M, Polascik TJ, Jones JS. Five-year biochemical progression-free survival following salvage whole-gland prostate cryoablation: defining success with nadir prostate-specific antigen. J Endourol. 2016;30(6):624-31.

19. Babaian RJ, Donnelly B, Bahn D, et al. Best practice statement on cryosurgery for the treatment of localized prostate cancer. JUrol. 2008;180(5):1993-2004.

20. Roach M 3rd, Hanks G, Thames H Jr., et al. Defining biochemical failure following radiotherapy with or without hormonal therapy in men with clinically localized prostate cancer: recommendations of the RTOG-ASTRO Phoenix Consensus Conference. Int J Radiat Oncol Biol Phys. 2006;65(4):965-74.

21. ValleLF, LehrerEJ, MarkovicD, etal. A systematic review and meta-analysis of local salvage therapies after radiotherapy for prostate cancer (MASTER). Eur Urol. 2021;80(3):280-92.

22. Taylor LG, Canfield SE, Du XL. Review of major adverse effects of androgen-deprivation therapy in men with prostate cancer. Cancer. 2009;115(11):2388-99.

23. Ginsburg KB, Elshafei A, Yu C, Jones JS, Cher ML. Avoidance of androgen deprivation therapy in radiorecurrent prostate 


\section{Oorspronkelijk artikel}

cancer as a clinically meaningful endpoint for salvage cryoablation. Prostate. 2017;77(14):1446-50.

24. Gotto GT, Yunis LH, Vora K, Eastham JA, Scardino PT, Rabbani F. Impact of prior prostate radiation on complications after radical prostatectomy. J Urol. 2010;184(1):136-42.

25. Cohen JK. Cryosurgery of the prostate: techniques and indications. Rev Urol. 2004;6(Suppl4):S20-S6.

26. Chen $\mathrm{CH}, \mathrm{Pu}$ YS. Proactive rectal warming during totalgland prostatecryoablation. Cryobiology. 2014;68(3):431-5

27. Cytron S, Paz A, KravchickS, Shumalinski D, Moore J. Active rectal wall protection using direct transperineal cryo-needlesfor histologically proven prostate adenocarcinomas. Eur Urol. 2003;44(3):315-20. discussion 20-1.

28. Wenske S, Quarrier S, Katz AE. Salvage cryosurgery of the prostate for failure after primary radiotherapy or cryosurgery: long-term clinical, functional, and oncologic outcomes in a large cohort at a tertiary referral centre. Eur Urol. 2013;64(1):1-7.

29. Castro Abreu AL de, Bahn D, Leslie S, et al. Salvage focal and salvage total cryoablation for locally recurrent prostate cancer after primary radiation therapy. BJU Int. 2013;112(3):298-307.

30. Heesakkers RA, Hövels AM, Jager GJ, et al. MRI with a lymph-node-specific contrast agent as an alternative to CT scan and lymph-node dissection in patients with prostate cancer: a prospective multicohort study. Lancet Oncol. 2008;9(9):850-6.

drs. Siberyn T. Nuijens, arts-onderzoeker

drs. L. Exterkate, aios radiotherapie

dr. Siebren Dijkstra, uroloog

dr. Max Peters, aios radiotherapie

dr. Diederik M. Somford, uroloog

dr. Henk Vergunst, uroloog 